\title{
ECONOMIA SOLIDÁRIA E FORMAÇÃO DE PREÇO (PREÇO JUSTO): ANÁLISE DOS CUSTOS E FORMAÇÃO DE PREÇO NA ECONOMIA POPULAR SOLIDÁRIA.
}

\author{
SILVA, Sara de Souza ${ }^{1}$ \\ Graduanda em Ciências Econômicas, bolsista de Iniciação Científica CNPq e membro da \\ Incubadora de Iniciativas da Economia Popular e Solidária da Universidade Estadual de Feira \\ Santana/Bahia/Brasil. \\ sarah.silva58@hotmail.com \\ LIMA, José Raimundo Oliveira² \\ Professor do Curso de Ciências Econômicas e Coordenador do Programa de Extensão e \\ Pesquisa \\ Incubadora de Iniciativas da Economia Popular e Solidária da Universidade Estadual de Feira \\ de \\ Santana/Bahia/Brasil. \\ joseraimundouefs@hotmail.com
}

\section{PALAVRAS-CHAVE: ECONOMIA POPULAR E SOLIDÁRIA - COMERCIO JUSTO - CUSTOS — FORMAÇÃO DE PREÇO.}

\section{INTRODUÇÃO}

Levando em consideração a dinâmica praticada na IEPS (Incubadora de Economia Popular e Solidária) ela se propõe se afirma como uma ação na luta pelo fortalecimento da cidadania e do desenvolvimento local e político, com o objetivo de articular as camadas populares para a geração de trabalho e renda, através da prática de incubação de grupos que se organizam nos princípios da economia popular e solidária tais como: cooperativas, associações, clubes de troca, entre outros, que realizam atividades de produção de bens, prestação de serviços justos e consumo solidário. As cantinas do módulo I e VII que atualmente são iniciativas de economia popular e solidária implantada na Universidade Estadual de Feira de Santana é um exemplo de resposta positiva na geração de trabalho e renda, e de integração da Universidade com a comunidade Externa de Feira de Santana, essa experiência reafirma permanentemente a

\footnotetext{
${ }^{1}$ Graduanda em Ciências Econômicas pela Universidade Estadual de Feira de Santana e Bolsista de Iniciação Científica CNPq da Incubadora de Iniciativa de Economia Popular e Solidária da Universidade Estadual de Feira de Santana/Bahia/Brasil.

${ }^{2}$ Professor Doutor do Curso de Ciências Econômicas e Coordenador do Programa de Extensão e Pesquisa Incubadora de Iniciativas da Economia Popular e Solidária da Universidade Estadual de Feira de Santana/Bahia/Brasil.
} 
importância da pesquisa e da atuação de pesquisadores e formadores no quadro de uma ação formativa que compõe a proposta pedagógica da IEPS que articula a integração do Ensino, Pesquisa e Extensão. Considerando a especificidade da atividade econômica conduzida pelos empreendimentos solidários as oficinas de formação são construídas coletivamente com a troca de saberes populares com o acadêmico. Considerando a especificidade da atividade econômica conduzida pelos empreendimentos solidários o presente projeto de pesquisa torna-se necessário, pois se propõe a realizar um estudo acadêmico e investigativo sobre a formação de preço na economia popular e solidária, como esse instrumento poderá ser relevante para uma analise econômica, voltado para os setores populares e como esse preço pode ser justo na perspectiva de desenvolvimento local a partir do estudo de caso do projeto cantina solidaria III.

\section{MATERIAL E MÉTODOS OU METODOLOGIA (ou equivalente)}

Por virtude do andamento da pesquisa e um aprofundamento maior em finanças e na gestão do projeto cantina III, surgiu à necessidade por parte da mesma em relação a custos e formação de preço. Sendo assim através de acompanhamentos contínuos em relação a grupo incubado houve uma demanda teórica por esse tema (preço justo) e como ele se forma nas iniciativas solidárias. Esse trabalho de pesquisa é de caráter coletivo que visa à compreensão da formação do preço que são praticados nas iniciativas solidárias. $\mathrm{O}$ método que será utilizado é a pesquisa participante (pesquisa ação), e teve como base teórica bibliográfica autores relacionados a este tipo de pesquisa.

Inicialmente estamos fazendo um estudo das bases teóricas específicas sobre economia solidária, economia popular e solidária, setores populares, comercio justo, desenvolvimento local e formação de preço (preço justo). Na sequência faremos a análise dos custos na visão econômica e contábil fazendo a comparação de ambas através de oficinas de formação com o grupo Sabores do Quilombo da cantina solidária III articuladas com o programa PIEPS (Programa de Iniciativas de Economia Popular e Solidária).

As oficinas de formação serão construídas coletivamente com a troca de saberes populares com o acadêmico. Portanto segundo BRANDÃO 2002 a educação popular não pode ser considerada como algo realizado como um acontecimento situado e datado, caracterizado por um esforço de ampliação do sentido do trabalho pedagógico a novas dimensões culturais, e a um vínculo entre a ação cultural e a prática política. A educação popular foi e prossegue sendo uma sequência de ideias e de propostas de um estilo de educação em que tais vínculos são reestabelecidos em diferentes momentos da história, tendo como foco de sua vocação um compromisso de ida - e - volta nas relações pedagógicas de teor político realizadas através de um trabalho cultural estendido a sujeitos das classes populares compreendidos como não beneficiários 
tardios de um "serviço", mas como protagonistas emergentes de um "processo".

\section{RESULTADOS E/OU DISCUSSÃO (ou Análise e discussão dos resultados)}

A compreensão efetivamente da relevância de proposições que visam o fortalecimento do desenvolvimento local por meio das finanças solidárias e a formação de preço (justo), articuladas entre as iniciativas de economia popular e solidária orientadas pelo Programa da Incubadora de Iniciativas de Economia Popular e Solidária da UEFS, foi pelo método da pesquisa - ação, essa metodologia adotada pela incubadora busca a troca de conhecimento acadêmico e saberes populares que consolidam as relações com os grupos incubados. Portanto realizam-se visitas às comunidades, acompanhamento financeiro quinzenal para que através desse meio consiga-se analisar a gestão tendo em vista a formação do preço justo e a observação de como elas fazem para conduzir-se sob a autogestão.

Logo a baixo está à decomposição dos custos de produção do grupo da Cantina (Sabores do quilombo) e a primeira oficina de formação de preço:

Tabela 1 - Preço dos Insumos

\begin{tabular}{cc}
\hline Insumos & Valor \\
Farinha & 0,02 \\
Camarão & 2,01 \\
Castanha & 0,46 \\
Amendoim & 0,24 \\
Leite de & \\
coco & 0,22 \\
Azeite & 0,14 \\
Cebola & 0,17 \\
Quentro & 0,04 \\
Cebolinha & 0,04 \\
Sal & 0,02 \\
Alho & 0,02 \\
Tomate & 0,34 \\
Pimentão & 0,10 \\
Quiabo & 0,13 \\
Feijão & 0,23 \\
Gengibre & 0,12 \\
\hline
\end{tabular}




\section{Total 4,28}

Elaboração própria, outubro/2016.

\section{Tabela 1- Custos Fixos}

\begin{tabular}{lc}
\hline Item & Valor \\
Trabalho & $\mathrm{R} \$ 0,02$ \\
Agua & $\mathrm{R} \$ 0,00$ \\
Energia & $\mathrm{R} \$ 0,05$ \\
Depreciação & $\mathrm{R} \$ 0,01$ \\
& \\
Total & $\mathbf{R} \mathbf{0 0 , 0 8}$ \\
\hline
\end{tabular}

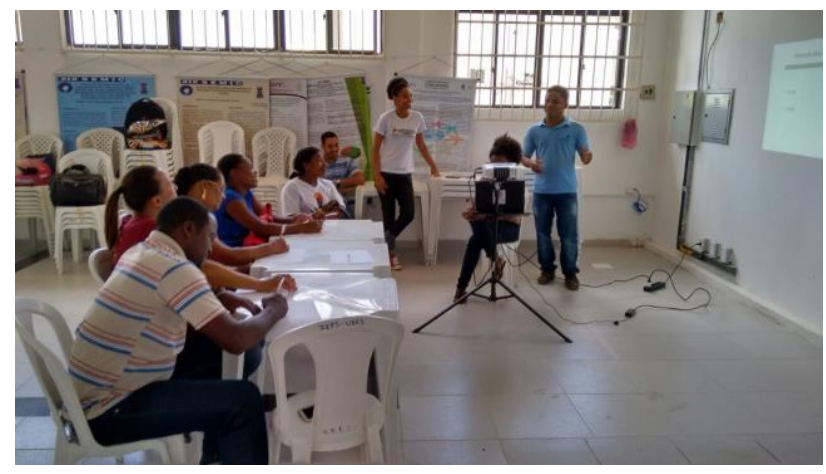

Figura 2: Primeira oficina de formação de

preço

O desenvolvimento desse plano de trabalho circulou principalmente em torno de dois principais objetivos que formam percebidos como principais no decorrer da finalização do plano de trabalho, pois destes se complementavam os demais, são eles: a) como se forma o preço nas iniciativas solidárias; e b) como o desenvolvimento local pode contribuir para a formação desse preço.

O primeiro objetivo trata basicamente do que esse preço que é formado nas iniciativas solidárias se difere da formação do preço dos empreendimentos tradicionais. O segundo objetivo investiga qual é a contribuição do desenvolvimento local traz para a formação de preço, pois o desenvolvimento local é uma estratégia para a manutenção dos custos de produção de produção. 


\section{CONSIDERAÇÕES FINAIS (ou Conclusão)}

É possível observar que a economia popular e solidária e o desenvolvimento local contribui para a construção do comercio justo e consequentemente para a formação do preço. Esse comercio segue a lógica de relação de proximidade visando a compra e a venda direta de produtos. Sendo assim o produtor sabe para quem vende como vende e a que preço irá vender que remunerará justamente a sua força de trabalho e remunera os custos de produção sem visar o lucro exacerbado na lógica do capital. Sendo assim o produtor conhecendo as necessidades do consumidor e conhecendo os custos de ponta a ponta tem a possibilidade de comercializar um produto de qualidade de custo-benefício. Portanto essa outra economia não se preocupa como modelos econômicos que maximizam os lucros e a utilidade no âmbito da economia de mercado, mais a reciprocidade e a solidariedade.

\section{REFERÊNCIAS}

LIMA, José Raimundo Oliveira. Economia Popular e Solidária e desenvolvimento local: relação protagonizada pela organicidade das iniciativas. Otra Economía, v. 10 , n. 18 , p. 3-17, 2016

MARTINS, E. Contabilidade de custos. Vol. 10. São Paulo: Atlas, 1980.

Polanyi, Karl. A grande transformação. Rio de Janeiro. Campos Ltda, 1972.

Projeto Incubadora de Iniciativas da Economia Popular e Solidária da Universidade

Estadual de Feira de Santana. Feira de Santana, Bahia, 2008.

Singer, Paulo. Introdução à Economia solidária-Editora Fundação Perseu Abramo, São Paulo, 2002, 125 p."

SMITH, A. A riqueza das nações. São Paulo. Martins Fontes, 2003

THIOLLENT, Michel. Metodologia da pesquisa-ação. São Paulo: Cortez,1986. 